\title{
Effect of antihypertensive treatment on blood-retinal barrier permeability to fluorescein in hypertensive Type 1 (insulin-dependent) diabetic patients with background retinopathy
}

\author{
H.-H.Parving ${ }^{1}$, M. Larsen ${ }^{2}$, E. Hommel ${ }^{1}$ and H.Lund-Andersen ${ }^{2}$ \\ ${ }^{1}$ Hvidöre Hospital, Klampenborg and ${ }^{2}$ Department of Ophthalmology, Gentofte Hospital, Gentofte, Denmark
}

\begin{abstract}
Summary. The effect of antihypertensive treatment on bloodretinal barrier leakage of fluorescein in background retinopathy was studied in nine hypertensive Type 1 (insulin-dependent) diabetic patients suffering from nephropathy. The patients were investigated before and after 7 ( 3 to 13) months of treatment with captopril $(n=8 ; 25$ to $100 \mathrm{mg}$ daily) and a diuretic, either frusemide ( $n=4 ; 80$ to $200 \mathrm{mg}$ daily) or bendrofluazide ( $n=2 ; 2.5 \mathrm{mg}$ daily). Retinal function was assessed by fundus photography, fluorescein angiography, vitreous fluorometry, and renal function by glomerular filtration rate, and albuminuria. The antihypertensive treatment induced a significant reduction $(p<0.05)$ in: blood pressure from $152 / 97 \pm 14 / 8 \mathrm{mmHg}$ to $134 / 82 \pm 11 / 6 \mathrm{mmHg}$; bloodretinal barrier leakage of fluorescein from $2.4 \pm 1.1$ to $1.4 \pm 0.5 \cdot 10^{-7} \mathrm{~cm} / \mathrm{second}$; albuminuria from 1391 (range:
\end{abstract}

$168-4852) \mu \mathrm{g} / \mathrm{min}$ to 793 (range: $35-2081) \mu \mathrm{g} / \mathrm{min}$. Glomerular filtration rate declined from $88 \pm 15$ to $78 \pm$ $23 \mathrm{ml} \cdot \mathrm{min}^{-1} \cdot 1.73 \mathrm{~m}^{2}(0.05<p<0.10)$. The metabolic control of the patients as reflected by their blood glucose and $\mathrm{HbA}_{1 \mathrm{c}}$ levels remained stable during the study. Our study suggests that systemic blood pressure elevation contributes to the abnormal blood-retinal barrier permeability to fluorescein characteristically found in diabetic background retinopathy and that this abnormality can be reversed during antihypertensive treatment.

Key words: Arterial blood pressure, antihypertensive treatment, diabetic retinopathy, diabetic nephropathy, Type 1 (insulin-dependent) diabetes, vitreous fluorometry.
Retinopathy is the most prevalent clinical manifestation of diabetic microangiography. Retinopathy, characterized by abnormal leakage of fluorescein through the blood-retinal barrier (BRB), can be demonstrated qualitatively by angiography and quantitatively by vitreous fluorometry [1-3]. A correlation between the severity of retinopathy and the magnitude of the $B R B$ dysfunction has been documented $[4,5]$, and a correlation between blood pressure and BRB permeability has been established in non-diabetic hypertensive subjects [6].

Cross sectional and longitudinal studies have identified several risk factors, e.g. arterial hypertension, for the development and progression of diabetic retinopathy [7-10]. Recently, elevated $\mathrm{HbA}_{1 \mathrm{c}}$ and even modestly elevated levels of diastolic blood pressure have been suggested as major predictors of the progression of background retinopathy in patients with long-standing Type 1 (insulin-dependent) diabetes [11]. Whether modification of these factors can prevent severe eye disease remains to be established. However, it should be stressed that effective antihypertensive treatment re- duces albuminuria and postpones renal insufficiency in diabetic nephropathy [12-15].

To evaluate the impact of systemic hypertension on the BRB permeability to fluorescein in diabetic background retinopathy we measured vitreous fluorometry before and during antihypertensive treatment in hypertensive Type 1 diabetic patients suffering from nephropathy.

\section{Subjects and methods}

\section{Subjects}

Nine untreated hypertensive Type 1 (insulin-dcpendent) diabetic patients suffering from background retinopathy and nephropathy were investigated (Table 1). All patients were characterized by persistent albuminuria ( $>300 \mathrm{mg} / 24 \mathrm{~h}$ ), serum creatinine $<150 \mu \mathrm{mol} / 1$, untreated arterial hypertension, age $<50$ years, onset of Type 1 diabetes before the age of 31 , and a background retinopathy neither previously treated by nor presently requiring laser photocoagulation as evaluated by ophthalmoscopy and fluorescein angiography. All subjects had 
Table 1. Clinical data in nine hypcrtensive Type 1 (insulin-dependent) diabetic patients suffering from background retinopathy and nephropathy

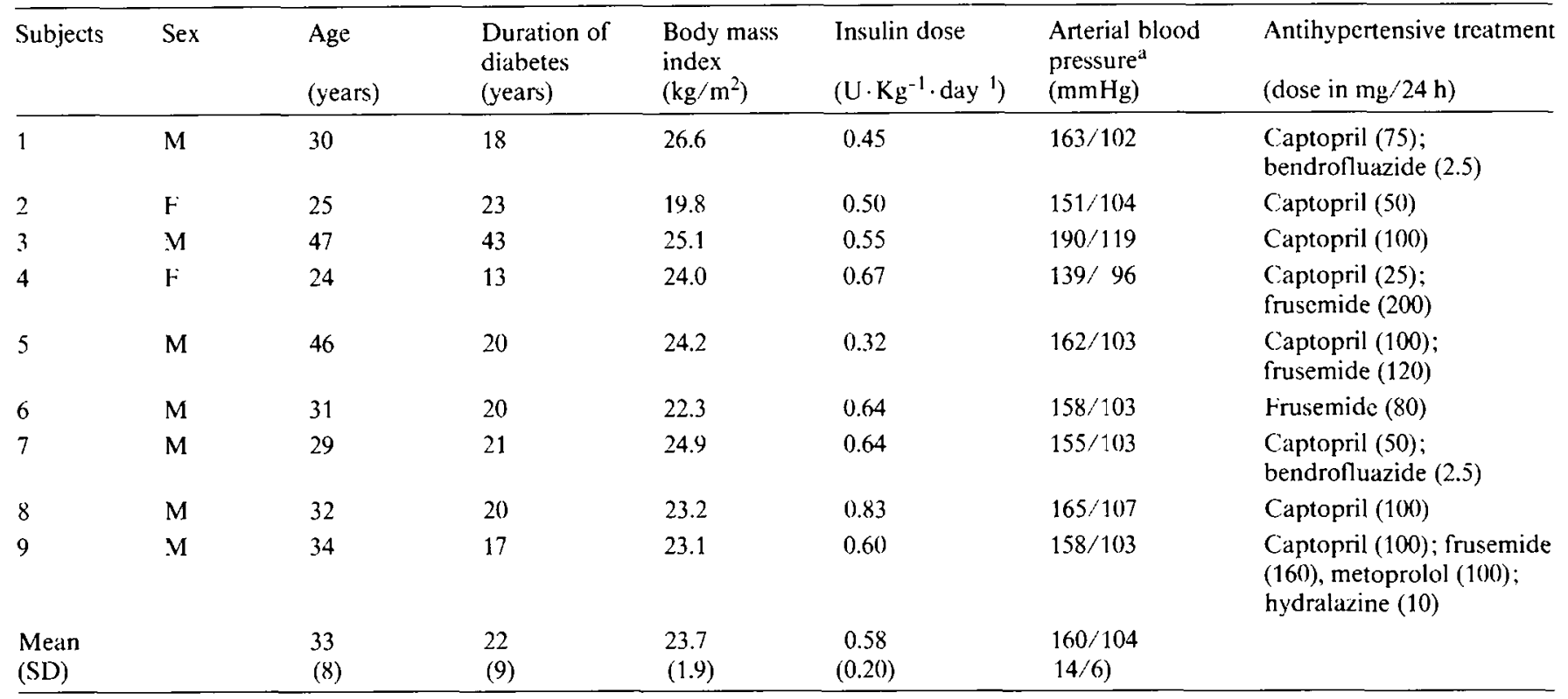

a Mean of last threc measurements performed in outpatient clinic before start of study

visual acuity of $6 / 9$ or better. All were insulin dependent from the time of diagnosis and received at least two daily injections of highly purified porcine insulin (mean dose $0.58 \mathrm{U} \cdot \mathrm{Kg}^{1} \cdot \mathrm{day}^{-1}$ ). They had a normal diabetic diet containing $45-55 \%$ carbohydrate, $30.35 \%$ fat, and $15-20 \%$ protein throughout the study, with no restriction of their salt or protein intake. A patient was designated as hypertensive if the mean of the last three blood pressure measurements performed in the outpatient clinic before the start of the study was equal to or higher than $160 / 90 \mathrm{mmHg}$. Nephropathy was diagnosed clinically according to previously described criteria [13]. The severity of the retinopathy was graded according to the ophthalmologic examination (see below). Initially, none of the patients were taking drugs other than insulin. After baseline investigation, treatment with captopril and a diuretic, frusemide or bendrofluazide, was started. The aim of the antihypertensive therapy was to achieve a stable reduction of diastolic blood pressure to below $90 \mathrm{mmHg}$ or at least a $10 \mathrm{mmHg}$ lowering of the mean arterial blood pressure (diastolic pressure plus one third of the pulse amplitude), or both. All patients gave their informed consent and the experimental design was approved by the local Ethical Committee.

\section{Methods}

All the investigations were carried out on one day between 08.30 and 15.30 hours. Patients had their normal breakfast and morning dose of insulin before the examination, during which they rested supine. They were allowed to stand up only when they needed to pass urine. They drank $150-200 \mathrm{ml}$ tap water per hour during the clearance study.

After a single i.v. injection of $100 \mu \mathrm{Ci}^{51} \mathrm{Cr}$-EDTA (at 09.00 hours) glomerular filtration rate (GFR) was calculated after determination of the plasma radioactivity in venous blood samples taken from the other arm 180, 200, 220 and $240 \mathrm{~min}$ after injection [16].

The small underestimation $(10 \%)$ of ${ }^{51} \mathrm{Cr}$-EDTA clearance versus clearance of insulin was corrected for by multiplying the ${ }^{51} \mathrm{Cr}$-EDTA clearance by 1.10 [17]. The mean coefficient of variation in GFR of each patient from day to day was $4 \%$. Urinary albumin excretion was measured during the $4 \mathrm{~h}$ clearance period by radioimmunoassay [18]. This assay has a sensitivity of $0.5 \mathrm{mg} / \mathrm{l}$ and a coefficient of variation between assays of $9 \%$.

All patients underwent an ophthalmologic examination (between 13.30 and 15.30 hours), including best corrected visual acuity (Snel-
Icn), slit-lamp biomicroscopy, ophthalmoscopy, fluorescein angiography (Canon CF-60Z, Kawasaki, Japan; Ilford HP5, ISO 400, Mobberly, (heshire, England) and quantitative posterior vitreous fluorometry. Our quantitative posterior vitreous fluorometry method had been described in detail previously [4]. After an i.v. injection of fluorescein $(14 \mathrm{mg} / \mathrm{kg}$ ), vitreous fluorescence was measured along the optical axis of the eye by an ocular fluorometer (Fluorotron Master, Coherent Inc., Palo Alto, Calif, USA). The fluorescence measured is the sum of the contribution of fluorescein glucuronide and fluorescein, which at the excitation and detection bands of the instrument $(420.490 \mathrm{~nm}$ and $530-630 \mathrm{~nm}$, respectively) have a fluorescence ratio of 0.20 or lower, depending on the spectral transmittance of the lens. Overall fluorescence was expressed in equivalent fluorescein concentration units.

The concentrations of fluorescein and fluorescein glucuronide in plasma ultrafiltrate were determined by high-pressure liquid chromatography [19]. Overall ultrafiltrate fluorescence expressed in equivalent fluorescein concentration units was calculated assuming a fluorescence intensity ratio of fluorescein glucuronide to fluorescein of 0.11 . This is in order to comply with the characteristics of equipment previously used for plasma ultrafiltrate fluorometry [20]. A simplified permeability index was calculated by dividing the vitrcous fluorescence curve integral from 2 to $8 \mathrm{~mm}$ in front of the retina by the log-interpolated plasma fluorescence integral from injection to vitreous measurement, which was between 60 and $70 \mathrm{~min}$ after the i.v. fluorescein injection. This calculation is based on equal transport properties through the BRB of fluorescein and fluorescein glucuronide, as discussed previously $[3,21]$. The normal value of the BRB permeability to fluorescein in healthy subjects below the age of 50 is $\leq 1.5 \cdot 10^{-7} \mathrm{~cm} /$ second (mean $+2 \mathrm{SD}$ ) [21]. The mean coefficient of variation in the BRB permeability to fluorescein of each subject from day to day was $10 \%$. Arterial blood pressure was measured with a Hawksley random zero device (cuff $25 \times 12 \mathrm{~cm}$ ) on the right arm. It was measured at least four times during each investigation between 09.00 and 10.00 hours and between 12.00 and 13.00 hours, and at each visit to the outpatient clinic (between 14.00 and 16.00 hours) after the patient had been supine for $10 \mathrm{~min}$ or more. Diastolic blood pressure was recorded at the disappearance of the Korotkoff sounds (phase V). Blood glucose concentration was measured hourly during the $4 \mathrm{~h}$ clearance period and on each visit to the clinic using a reflectance meter (Reflomat, Boehringer-Mannheim, Ingelheim, FRG). Stable $\mathrm{HbA}_{1 \mathrm{c}}$ was measured at each investigation (normal range $4.1-6.1 \%$ of the total $\mathrm{Hb}$ value) [22]. 
Table 2. Arterial blood pressure, blood-retinal barrier permeability to fluorescein, glomerular filtration rate, albuminuria, blood glucose concentration, $\mathrm{HbA}_{1 \mathrm{c}}$ before and during antihypertensive treatment in nine Type 1 (insulin-dependent) diabetic patients suffering from background retinopathy and nephropathy

\begin{tabular}{|c|c|c|c|c|c|c|c|c|c|c|c|c|c|}
\hline \multirow[t]{2}{*}{ Subjects } & \multirow[t]{2}{*}{$\begin{array}{l}\text { Treatment } \\
\text { period } \\
\text { (months) }\end{array}$} & \multicolumn{2}{|c|}{$\begin{array}{l}\text { Arterial blood } \\
\text { pressure } \\
(\mathrm{mmHg})\end{array}$} & \multicolumn{2}{|c|}{$\begin{array}{l}\text { Blood-retinal bar- } \\
\text { rier permeability } \\
\left(10^{-7} \mathrm{~cm} \cdot \mathrm{s}^{1}\right)\end{array}$} & \multicolumn{2}{|c|}{$\begin{array}{l}\text { Glomerular } \\
\text { filtration rate } \\
\left(\mathrm{ml} \cdot \mathrm{min}{ }^{1} \text {. }\right. \\
\left.1.73 \mathrm{~m}^{2-1}\right)\end{array}$} & \multicolumn{2}{|c|}{$\begin{array}{l}\text { Albuminuria }{ }^{a} \\
(\mu \mathrm{g} / \mathrm{min})\end{array}$} & \multicolumn{2}{|c|}{$\begin{array}{l}\text { Blood glucose } \\
(\mathrm{mmol} / \mathrm{l})\end{array}$} & \multicolumn{2}{|c|}{$\mathrm{HbA}_{\mathrm{Ic}}(1 / 0)$} \\
\hline & & before & during & before & during & before & during & before & during & \multicolumn{2}{|c|}{ beforc during } & before & during \\
\hline 1 & 7 & $141 / 88$ & $138 / 81$ & 4.2 & 1.9 & 102 & 94 & 168 & 35 & 15.6 & 11.0 & 8.7 & 9.1 \\
\hline 2 & 7 & $154 / 100$ & $124 / 77$ & 1.5 & 1.3 & 81 & 57 & 2588 & 1379 & 15.5 & 8.5 & 8.0 & 7.8 \\
\hline 5 & 7 & $145 / 92$ & $139 / 85$ & 2.0 & 1.9 & 85 & 62 & 1391 & 683 & 8.6 & 3.5 & 8.7 & 7.0 \\
\hline 6 & 3 & $185 / 110$ & $135 / 72$ & 1.5 & 1.1 & 56 & 48 & 2717 & 1688 & 11.1 & 10.2 & 8.4 & 7.8 \\
\hline 7 & 6 & $164 / 100$ & $150 / 90$ & 1.5 & 1.4 & 88 & 94 & 1135 & 793 & 12.6 & 10.7 & 9.2 & 8.2 \\
\hline 8 & 4 & $150 / 95$ & $141 / 80$ & 2.4 & 1.2 & 108 & 120 & 309 & 113 & 5.7 & 6.7 & 7.4 & 7.8 \\
\hline 9 & 13 & $140 / 110$ & $115 / 85$ & 2.6 & 1.2 & 95 & 68 & 48.52 & 1218 & 6.8 & 10.9 & 7.2 & 8.2 \\
\hline Mean & 7 & $152 / 97$ & $134 / 82$ & 2.4 & 1.4 & 88 & 78 & 1391 & 793 & 11.2 & 10.1 & 8.3 & 8.0 \\
\hline
\end{tabular}

${ }^{a}$ Mean and range indicated

\section{Statistical analysis}

Wilcoxon's non-parametric test for paired comparison was used for statistical analysis. Mean values are given \pm standard deviation (mean $\pm S D$ ). As albuminuria values are not normally distributed, median and range are used.

\section{Results}

Arterial blood pressure fell in all nine patients (from $152 / 97 \pm 14 / 8 \mathrm{mmHg}$ to $134 / 83 \pm 11 / 6 \mathrm{mmHg}$ ) during hypotensive therapy, $p<0.01$ (Table 2 ). The BRB permeability to fluorescein decreased in all patients during antihypertensive treatment (before therapy $2.4 \pm 1.1$, during therapy $1.4 \pm 0.5 \cdot 10^{.7} \mathrm{~cm} \cdot \mathrm{s}^{-1}, p<0.01$ ) (Table 2). The BRB permeability was in the majority of the patients lowered to values comparable with those found in normal subjects. No significant correlation between the changes in the two above-mentioned variables was found.

As evaluated from the fundus pictures and the angiograms in the macular area, two patients (no. 1 and 4) had 5 to 10 red spots and haemorrhages while the remaining patients had less than 5 of these lesions. All patients had less than 5 soft and/or hard exudates, and macular oedema was not present. The highest BRB permeability was detected in the two patients (no.1 and 4) with the severest morphological lesions. Significant differences were neither observed on fundus pictures nor on the angiograms before or during antihypertensive treatment. Lens transmission and fluorescence were not significantly changed between the two examinations. Visual acuity was $\geq 6 / 9$ in all patients, and did not change during the study. Albuminuria diminished in all patients $(p<0.01)$ and GFR declined from $88 \pm 15$ to $78 \pm 23 \mathrm{ml} \cdot \mathrm{min}^{1} \cdot 1.73 \mathrm{~m}^{2}-1$ during the seven months of antihypertensive treatment (Table 2, $0.05<p<0.10$ ). The metabolic control of the patients as reflected by their blood glucose and $\mathrm{HbA}_{1 \mathrm{c}}$ levels remained about the same during the study.

\section{Discussion}

The major novel observation in our study is the finding that effective antihypertensive treatment with an angiotensin converting enzyme inhibitor, captopril, and diuretics has a beneficial effect on the breakdown of the $B R B$ in hypertensive Type 1 diabetic patients with background retinopathy. The BRB permeability to fluorescein was normalized in six out of the nine patients during antihypertensive therapy.

Our study was not a double blind, randomized, parallel control trial, which is the ideal design. Such a trial, however, can hardly be considered to be ethical in hypertensive Type 1 diabetic patients with nephropathy because several studies have reported a beneficial effect of antihypertensive treatment on albuminuria and kidney function in these patients [12-15]. Furthermore, the natural course of diabetic background retinopathy is characterized by a progressive rise in BRB permeability to fluorescein ranging from 9 to $29 \%$ per 6 months [23, 24]. Recently, we have confirmed this finding in a prospective study of normotensive Type 1 diabetic patients suffering from background retinopathy and nephropathy, since a yearly rise in BRB permeability of $41 \%$ was documented (the present investigators).

A key question is the exact interpretation of the leakage in terms of physiological and biological transport phenomena (permeability and surface area (PS product)). Factors related to changes in lens absorption and differences in plasma fluorescein decay can be excluded, since plasma fluorescein was incorporated in 
the calculations and since the lens transmittance as evaluated by lens autofluorescence was unchanged during the observation period. The leakage can, thus, be interpreted in terms of the permeability factor or a PS product [4]. It is not possible from the present data to elucidate conclusively which of these two factors is responsible for the change in leakage.

$\Lambda$ real change in permeability may be due to changes in the structure of the BRB or due to a diminished transcapillary hydrostatic driving force, particularly capillary pressure. A reduction in blood flow per se induced by treatment cannot explain our finding, since the transcapillary passage of fluorescein, due to the minimal permeability is limited by diffusion and not by blood flow [3, 24]. Furthermore, captopril reduces neither cerebral blood flow nor impairs its autoregulation [26]. Recently, Sinclair et al. [27] have found impaired autoregulation of retinal blood flow in diabetic background retinopathy and nearly complete lack of autoregulation in proliferative diabetic retinopathy. Furthermore, the diabetic condition is usually characterized by a generalized vasodilatation [28]. These findings will create a condition where systemic hypertension will more easily be transmitted to the retinal microcirculation resulting in capillary hypertension. Circumstantial evidence supports this suggestion, since the present reduction in BRB permeability to fluorescein is nearly 5.0 times higher per $\mathrm{mmHg}$ compared with our previous findings in essential arterial hypertension [6]. Direct measurements have documented capillary hypertension in normotensive diabetic rats [29-31]. These findings provide a likely explanation for the damaging effect of hypertension in diabetic retinopathy [7-11] and for the protective effects on retinopathy of diminished retinal blood flow (pressure), as reviewed by Rand et al. [30]. Scatter photocoagulation is a treatment that mimics the effects of the conditions by reducing the retinal blood flow (pressure). The simplest explanation for the observed reduction in the BRB leakage of fluorescein may, therefore, be the correct one - a reduction of retinal capillary pressure induced by the antihypertensive treatment. Improved metabolic control can be ruled out as the cause of the reduction in fluorescein leakage in our study, since the patient's metabolic control as reflected by the $\mathrm{HbA}_{1 \mathrm{c}}$ and blood glucose levels remained practically unchanged.

The observed reduction in albuminuria is in complete agreement with previous findings during antihypertensive treatment of diabetic nephropathy [12-15]. Approximately half of our patients had a stepwise reduction in GFR of $>10 \%$ of the GFR before treatment, a phenomenon frequently observed at the start of aggressive antihypertensive treatment [12-15]. Impaired autoregulation of GFR has been suggested as an important contributing factor [33].

In conclusion, the finding that angiotensin converting enzyme inhibition with captopril and a diuretic can arrest or even reverse the progressive rise in $\mathrm{BRB}$ permeability to fluorescein in hypertensive Type 1 diabetic patients with background retinopathy is encouraging but must be interpreted with caution. The crucial question, requiring longer-term follow-up, has not been answered: can the progression of diabetic retinopathy be reduced or even prevented in hypertensive diabetic patients by captopril or other antihypertensive treatment regimens?

\section{References}

1. Kohner EM, McLeod D, Marshall J (1982) Diabctic eye disease. In: Keen $\mathrm{H}$, Jarrett $J$ (eds) Complications of diabetes, 2nd edn. Fidward Arnold, London, pp 19-108

2. Cunha-Vaz JG, Abreu JR, Campos AJ, Figo GM (1975) Early breakdown of the blood-retinal barrier in diabetes. Br J Ophthalmol 59: 649-656

3. Lund-Andersen H, Krogsaa B, La Cour MN, Larsen J (1985) Quantitative vitreous fluorophotometry applying a mathematical model of the cye. Invest Ophthalmol Vis Sci 26:698 710

4. Krogsaa B, Lund-Andersen H, Mehlsen J, Sestoft L (1987) Bloodretinal barrier permeability versus diabetes duration and retinal morphology in insulin dependent diabetic patients. Acta Ophthalmol 65: 686-692

5. Kohner EM, Plehwe WE, Sleightholm MA (1988) Does vitreous fluorophotometry reflect the severity of early diabetic retinopathy? ARVO 29:260 ( $\triangle$ bstract)

6. Krogsaa B, I.und-Andersen H, Parving H-H, Bjældager P (1983) The blood-retinal barrier permeability in essential hypertension. Acta Ophthalmol 61: $541-544$

7. Kornerup T (1957) Blood pressure and diabetic retinopathy. Acta Ophthalmol 35: 163.174

8. West KM, Frdreich LJ, Stober JA (1980) A detailed study of risk factors for retinopathy and nephropathy in diabetes. Diabetes 29 : 501.508

9. Knowler WC, Bennett PA, Ballintine EJ (1980) Increased incidence of retinopathy in diabetics with elevated blood pressure. N Fingl J Med 302: 645-650

10. Klc:n R, Klein BEK, Moss SE (1985) A population-based study of diabetic retinopathy in insulin-using patients diagnosed before 30 years of age. Diabetes Care 8: 71-76

11. Janka HU, Rand LI, Warram JH, Krolewski AS (1988) Glycosylated haemoglobin and diastolic blood pressure are the major predictors of progression of background diabetic retinopathy in Type 1 (insulin-dependent) diabetes. Diabetologia 31: 504 A (Abstract)

12. Mogensen CE (1982) Long term antihypertensive treatment inhibiting progression of diabetic nephropathy. $\mathrm{Br}$ Med $\mathrm{J} 285$ : 685688

13. Parving H-H, Andersen AR, Smidt UM, Svendsen PA (1983) Farly aggressive antihypertensive treatment reduces rate of decline in kidney function in diabetic nephropathy. Lancet I: 1175. 1179

14. Parving $\mathrm{H}-\mathrm{H}$, Andersen $\mathrm{AR}$, Smidt UM, Hommel E, Mathiesen ER, Svendsen PA (1987) Effect of antihypertensive treatment on kidney function in diabetic nephropathy. Br Med J 294: 14431447

15. Parving H-H, Hommel F, Smidt UM (1988) Protection of kidney function and decrease in albuminuria by captopril in insulin dependent diabetics with nephropathy. Br Med J 297: 1086-1091

16. Brochner-Mortensen J (1972) A simple method for determination of glomerular filtration rate. Scand J Clin Lab Invest 30: 271-274

17. Brochner-Mortensen J, Rodbro P (1976) Selection of routine method for determination of glomerular filtration ratc in adult patients. Scand J Clin Lab Invest 36:35-45 
18. Miles DW, Mogensen CE, Gundersen HJG (1970) Radioimmunoassay for urinary albumin using a single antibody. Scand J Clin Lab Invest 26:5 . 11

19. Larsen M, Loft S, Hommel E, Lund-Andersen H (1988) Fluorescein and fluoresccin glucunide in plasma after intravenous injection of fluoresccin. Acta Ophthalmol 66: 427-432

20. Lund-Andersen H, Krogsaa B, Jensen PK (1982) Fluorescein in human plasma in vivo. Acta Ophthalmol 60: 709-716

21. Krogsaa B, Lund-Andersen H, Mehlsen J. Sestoft L (1986) The blood-retinal barrier permeability to fluorescein in normal subjects and in juvenile diabetics without retinopathy. Acta Ophthalmol 64: 173-179

22. Mortensen HB (1980) Quantitative determination of haemoglobin $\mathrm{A}_{1 \mathrm{c}}$ by thin layer isoelectric focusing. J Chromatogr 182:325-333

23. Lauritzen T, Frost-Larsen K, Svendsen PA, Larsen H-W, Deckert T, Christiansen JS, Parving H-H, Binder C, Nerup J, Deckert M, Larsen A, Lorup B, Bojsen J, Bech-Jansen L (1982) Effect of 6 month of strict metabolic control on eye and kidney function in insulin-dependent diabetics with background retinopathy. Lancet I: $121-124$

24. Lund-Andersen H (1979) Transport of glucose from blood to brain. Physiol Rev 59: 305-352

25. Cunha-Vaz JG, Mota CC, Leitc FC, Abreu JR, Ruas MA (1985) Effect of sulindac on the permeability of the blood-retinal barrier in early diabetic retinopathy. Arch Ophthalmol 103: 1307.1311

26. Paulson O, Jarden DB, Vorstrup S, Holm S, Godtfredsen J (1986) Effect of captopril on the cerebral circulation in chronic heart failure. Eur J Clin Invest 16: 124-132

27. Sinclair SH, Graunvald JE, Riva C, Braunstein SL, Nichols CW, Schwartz S (1982) Retinal vascular autoregulation in diabetes mellitus. Ophthalmology 89: $748 \cdot 750$
28. Parving H-H, Viberti GC, Keen H, Christiansen JS, Lassen NA (1982) Hemodynamic factors in the genesis of diabetic microangiopathy. Metabolism 32: 943-949

29. Hostetter TH, Troy JL, Brenner BM (1981) Glomerular hemodynamics in experimental diabetes. Kidney Int 19:410-415

30. Jensen PK, Steven K, Blæhr H, Christiansen JS, Parving H-H (1986) Effects of indomethacin on glomerular hemodynamics in experimental diabetes. Kidney Int 29: 490-495

31. Korthuis RJ, Pitts VH, Granger DN (1987) Intestinal capillary filtration in experimental diabetes mellitus. Am J Physiol 253: G20-G25

32. Rand LI, Krolewski AS, Aiello LM, Warram JA, Baker RS, Maki T (1985) Multiple factors in the prediction of risk of proliferative diabetic retinopathy. N Engl J Med 313: 1433 1438

33. Parving H-H, Kastrup J, Smidt UM, Andersen AR, Feldt-Rasmussen B, Christiansen JS (1984) Impaired autoregulation of glomerular filtration rate in Type 1 (insulin-dependent) diabetic patients with nephropathy. Diabetologia $27: 547.552$

Received: 17 January 1989

and in revised form: 17 April 1989

Dr. H.-H. Parving

Hvidöre Hospital

Emiliekildevej 1

DK-2930 Klampenborg

Denmark 